\title{
Design, Fabrication and Performance Evaluation of Domestic Gas Oven
}

\author{
Genitha $\mathrm{I}^{1}$ and Lakshmana Gowda B $\mathrm{T}^{2}$ and John Diamond Raj ${ }^{3}$ \\ ${ }^{I}$ (Assistant Professor, Department of Food Process Engineering, Vaugh School of Agricultural Engineering and \\ Technology, Sam Higginbottom Institute of Agriculture, Technology and Sciences, (Deemed-to-be University), \\ Allahabad-211 007, U P, India) \\ ${ }^{2}$ (M.Tech Food Technology Student, Department of Food Process Engineering, Vaugh School of Agricultural \\ Engineering and Technology, Sam Higginbottom Institute of Agriculture, Technology and Sciences, (Deemed- \\ to-be University), Allahabad-211 007, U P, India) \\ ${ }^{3}$ (Assistant Professor, Department of Food Process Engineering, Vaugh School of Agricultural Engineering and \\ Technology, Sam Higginbottom Institute of Agriculture, Technology and Sciences, (Deemed-to-be University),
} Allahabad-211 007, U P, India)

\begin{abstract}
A study, to design, fabricate and performance evaluation of the domestic gas oven was carried. The oven was designed and was fabricated with an outer dimension of $450 \mathrm{~mm}$ length $\times 350 \mathrm{~mm}$ width $\times 380 \mathrm{~mm}$ height made up stainless steel and the inner dimension of $380 \mathrm{~mm}$ length $\times 310 \mathrm{~mm}$ width $\times 340 \mathrm{~mm}$ height made up of aluminum sheet and silicone rubber and asbestos used as an insulator. The gas burner was fixed in the stand for baking and the deflector plate placed in the bottom of the baking chamber and the bimetallic thermometer was fixed in the oven and provided with the vent for the removal of humid air. The oven was tested in order to determine its function the model works on natural convection. The effectiveness was analyzed by baking cake, cookies and muffins. Results showed that the cake was baked in $28 \mathrm{~min}$ at a temperature of $180^{\circ} \mathrm{C}$ it depends on the size of the cake, cookies took $10 \mathrm{~min}$ at a temperature of $150^{\circ} \mathrm{C}$ and the muffins were baked in $13 \mathrm{~min}$ at a temperature of $180^{\circ} \mathrm{C}$ showing higher energy efficiency by reducing the energy, cost and the time of baking.
\end{abstract}

Keywords: - Design, Fabrication, Gas Oven, Natural Convection, Energy Efficiency.

\section{INTRODUCTION}

Baking is the oldest and most popular food processing techniques that uses the prolonged dry heat by convection rather that the thermal radiation normally in an oven, but also in ashes or on hot stones. It is a complex simultaneous heat and mass transfer process commonly applied in food industries.

A baking oven is the most widely used appliance in food service industry. An oven can be simply described as a fully enclosed thermally insulated chamber use for the heating, baking or drying of a substance. In a baking oven, the hot air flows over the baking material either by natural convection or forced by a fan, the convection heat transfer from the air, the radiation heat transfer from the oven heating surfaces, and the conduction heat transfer across contact area between product and metal surface. The moisture in the food material simultaneously diffuses toward the surfaces, then, it transfers from the surface by convection, and the product loses moisture with continuous movement of the oven ambient air. These are the simultaneous momentum, heat and moisture transfer mechanisms within a baking product (Tong and Lund 1990; Ozilgen and Heil 1994) and between the product and its environment (Carvalho and Martins 1993), which theoretically are well known. Commercially, ovens are available in the various configurations like electric ovens, micro oven and wood oven etc.

Electric ovens are the direct fired oven, which effectively distribute heat while being powered by electricity, although this can often result in a higher heating cost for the consumer. Many prefer this type of oven because they tend to use dry heat, which helps prevent the buildup of rust. Electric ovens also feature a thermostat that controls the oven's temperature electronically, and many have top, bottom, or rear grill elements. Electric ovens can take longer to heat, but they are relatively inexpensive in cost compared to other types of ovens.

Wood-fired ovens are indirectly fired ovens that use wood fuel for cooking. While the traditional wood-fired oven is like a masonry oven (mud oven), such ovens can also be built out of cob or iron. Wood-fired ovens are distinct from wood-fired stoves that have a hot cooking surface for pots and pans like electric stove. A wood stove may also have an oven separate from the fire chamber. Regardless of material they all have an oven chamber consisting of a floor (or hearth), a dome and an entry (oven opening). The wood fired oven has an advantage of the less capital requirement, ease of construction and similarly the wood fired has the disadvantage 
of longer baking time, the product has not baked uniformly and has the problem of the changing the original flavor of the product.

Gas oven one of the first recorded uses of a gas stove and oven referenced a dinner party in 1802 hosted by Zachaus Winzler, where all the food was prepared either on a gas stove or in its oven compartment. In 1834, British inventor James Sharp began to commercially produce gas ovens after installing one in his own house. In 1851, the Bower's Registered Gas Stove was displayed at the Great Exhibition. This stove would set the standard and basis for the modern gas oven. Notable improvements to the gas stove since include the addition of the thermostat which assisted in temperature regulation; also an enamel coating was added to the production of gas stoves and ovens in order to help with easier cleaning.

Gas oven is one which works by the liquefied petroleum gas for the baking of the bread, cake and biscuit.The major operational principle of the gas oven is the process of heat transfer. Heat transfer tends to occur whenever there is a temperature difference, and the ways in which heat may be transferred in the gas oven that is convection.

Convection is the transfer of energy from one place to another by the motion of a mass of materials between the two points. In a natural convection, the motion of the fluid is entirely as a result of differences in density resulting from temperature differences. Naturally, convection occurs when a solid surface is in contact with a fluid of different temperature from a surface. Density differences provide the force required to move the fluid (moisture) in the food.

In the oven, the fluid involved is the enclosed air and the burner surface, which provides the solid surface, while the oven walls serve as the solid surfaces. The rate at which heat is transferred across an enclosed oven is calculated from a coefficient based upon the temperature differences of the surfaces.

Study of baking oven is important because it could lead to a more efficient process of baking favorable to energy efficiency and better product quality (Fellows, 2000). The baking process usually requires significant energy consumption as relatively high temperature is applied in order to remove moisture in bakery products and create desired texture. Analysis and optimization of baking process and equipment have been conducted for minimizing energy consumption (Therdthai et al., 2003).

In recent days the electric oven users are facing a problem due to the erratic power cuts in middle of the operations, these causes the loss of the quality of the end product and the loss of the capital and the electric oven consumes a more energy. The use of gas as the energy source for baking oven is a commercial necessary in most of the regions because the electricity by comparison is prohibitively expensive. So the present study was carried with the following objectives.

1. To design and fabricate a domestic gas oven.

2. To study the performance evaluation of the designed gas oven.

\section{MATERIALS AND METHODOLOGY}

The design of the gas oven was done by using the software 3D solid works which shows the pictorial views, lines and dimensions for the fabrication. The design of the oven as shown in diagram.

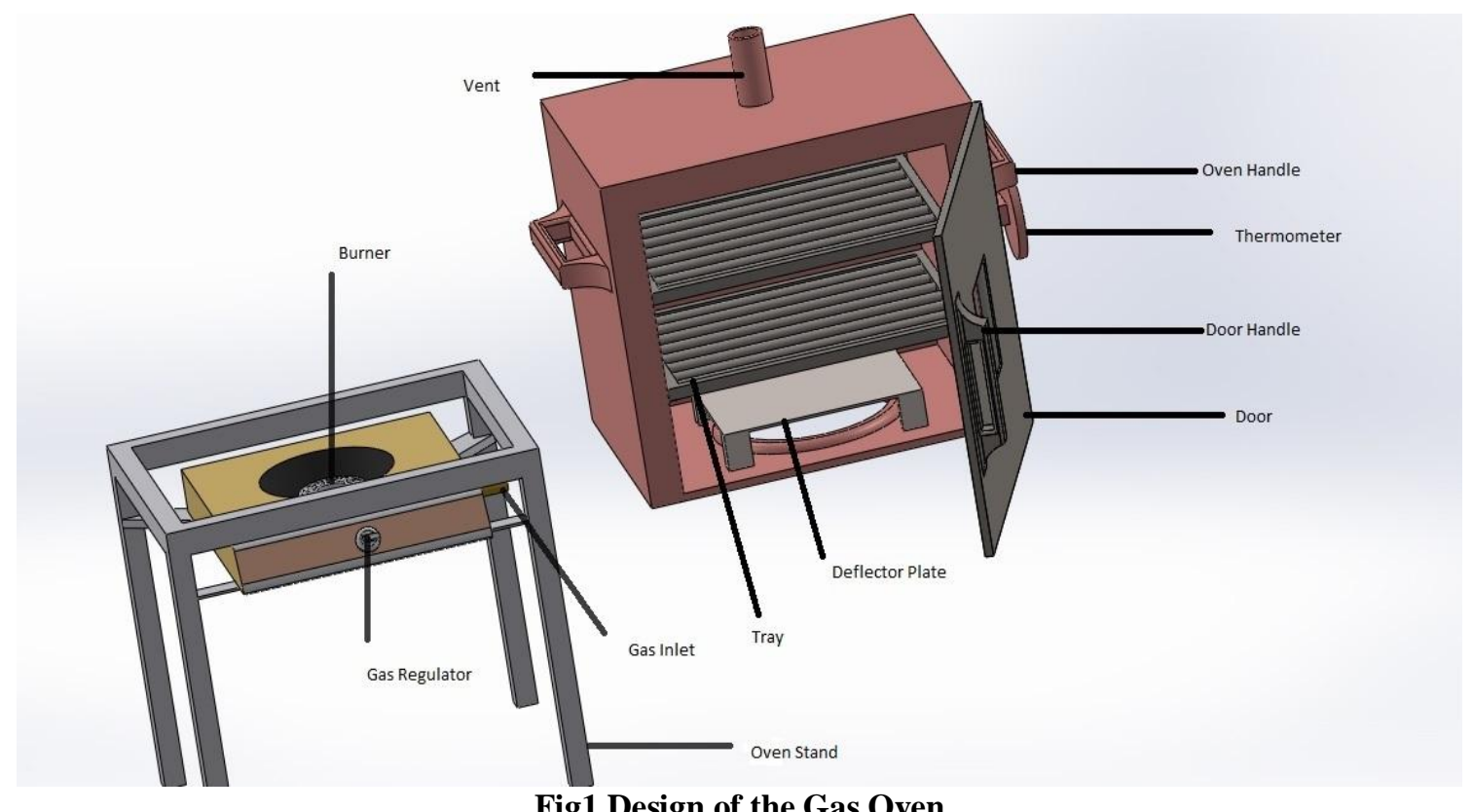

Fig1 Design of the Gas Oven 
A new design of the baking gas oven has been fabricated according to the design with the use of indigenous material. The oven consist of housing unit, thermometer, outlet nozzle, heating gas burner. The housing unit represents the entire out look of the baking oven. The housing unit of the gas oven was made up of three layers that was outer stainless steel of thickness 26 gauge with the dimension $450 \times 350 \times 380$ (Length $\times$ Width $\times$ Height) $\mathrm{mm}$, inner layer was made out of aluminum sheet of thickness 24 gauge with the dimension of $380 \times 310 \times 340 \mathrm{~mm}$ (Length $\times$ width $\times$ height) and the middle layer of the gas oven consist thermal insulating material such has silicone rubber and the asbestos sheet all four sides of the oven. These two material acts as an insulator to avoid the loss of the heat from the inner baking chamber to the outside ensures for the even baking of the product in the baking chamber. The door of the gas oven was made up of the stainless steel and the asbestos sheet of thickness $5 \mathrm{~mm}$ was placed in between the steel plate to avoid the loss of heat through the door and in the front of the door provided with the toughened glass to monitor the inside baking product without opening the door.

The single stove burner was attached to the stand so that the baking oven chamber can be easily placed on the stand. The stand kept at a height of $300 \mathrm{~mm}$ from the ground level so that the burner receives the enough oxygen for the burning of the gas and the flame coming from the burner directly enters the baking chamber for baking and there was less loss of the heat and the flame controlling knob was provided to control the flame in turn controls the temperature in inside baking chamber. The base of the inner baking chamber was provided with the deflector plate of the thickness of $3 \mathrm{~mm}$ with dimension of $240 \times 200$ (length $\times$ width) mm placed at a hight of $40 \mathrm{~mm}$ from the base of the oven to avoid the direct flame from the burner to the baking chamber and to the even distribution of the heat throughout the baking chamber as shown in the diagram.

The bimetallic thermometer ranging the temperature from 0 to $300^{\circ} \mathrm{C}$ was placed in the side wall of the oven. The thermometer sensor was placed in the center portion of the baking chamber to ensure that the thermometer should detect the temperature of the both the lower and the upper layer of the baking oven. The oven provided with the vent at the top of the baking oven connected from the inner baking chamber for the continuous removal of the hot and the humid air from the inner baking chamber. The baking oven was provided with the handles in both the sides to remove or/and to place the oven above the burner stand.

The two trays was provided in the oven, lower tray was made of the perforated aluminium mesh of thickness $3 \mathrm{~mm}$ to place the small baking tins and the oven works by the natural convection it helps for the movement of the hot air to the upper tray of the oven and the upper tray was also made up of the aluminium mesh. The distance of upper tray from the top of the oven was kept at $120 \mathrm{~mm}$ distance and the distance from upper tray to the lower tray was kept at $120 \mathrm{~mm}$ and the distance from the lower tray to the base of oven was $100 \mathrm{~mm}$

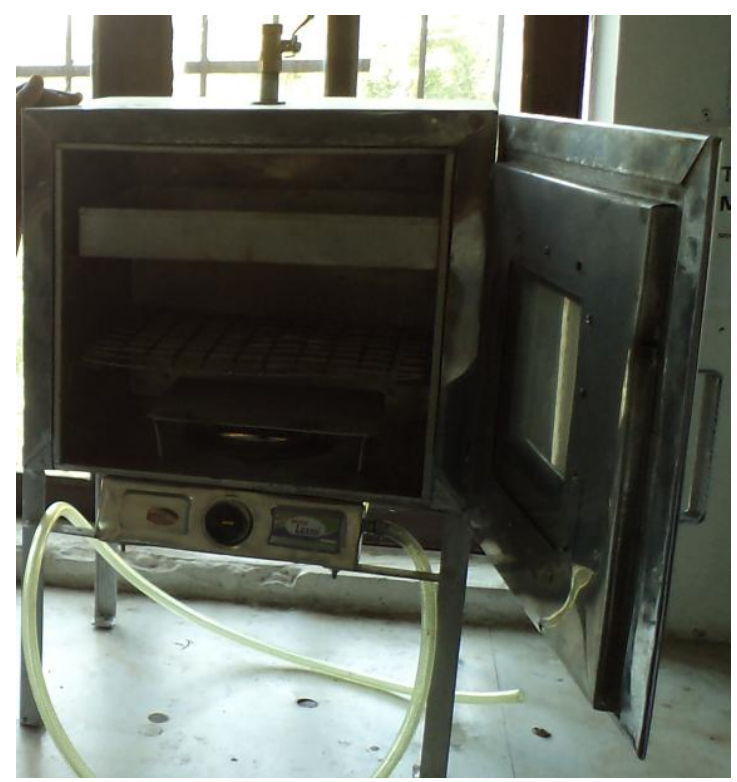

Fig 2.1 Fabricated Gas Oven

\section{RESULTS AND DISCUSSION}

The gas baking oven was put to test in order to determine its functionality and the effectiveness through baking some food items like cakes, cookies and the muffins. The oven works majorly by convection mode of heat transfer. The experiment was performed for the each of them while measurement were taken with respect to the corresponding time taken for the baking of the particular food items. 


\subsection{Baking of Cake}

The cakes of the different size was baked in the gas oven at a temperature range of the $170-180^{\circ} \mathrm{C}$. The time taken by the gas oven for the baking of the cakes shown in the Table 3.1. From this its shows that, has size of the cake increases the time required for the baking also increases. The quality parameters like the volume, color and the texture of the cake was well developed and was acceptable.

Table 3.1 Baking Time of the Cakes

\begin{tabular}{|l|c|}
\hline \multicolumn{1}{|c|}{ Product } & Time taken to bake \\
\hline Cake (small size) & $19 \mathrm{~min}$ \\
\hline Cake (medium size) & $28 \mathrm{~min}$ \\
\hline
\end{tabular}

\subsection{Cookies and Muffins}

The cookies was baked in the gas oven, the time taken for the baking of the cookies was shown in the table at the baking temperature of $150^{\circ} \mathrm{C}$ and the muffins was baked in an gas oven the time taken for baking shown in table 3.2 at a temperature of $180^{\circ} \mathrm{C}$. Cookies and the muffins are baked evenly and the texture and the color of the cookies was acceptable

Table 3.2 Baking Time of the Cookies and Muffins

\begin{tabular}{|c|c|}
\hline Product & Time taken for baking \\
\hline Cookies & $10 \mathrm{~min}$ \\
\hline Muffins & $13 \mathrm{~min}$ \\
\hline
\end{tabular}

\section{CONCLUSION}

From this study it is evidently clear that the designed gas oven can be better used for the baking of the cakes, cookies and all the bakery products with good quality parameters like color, texture and the taste and good volume in the fermented products and also the pre heating time of the gas oven was also reduced this in turn consumes very less energy and the time of the baking and reduces the overall working cost. This can be used for small entrepreneurs and can be popularized in areas where power cuts are more frequent and power is available for limited hours. This gas oven having the disadvantage of the controlling the temperature inside the baking chamber.

\section{ACKNOWLEDGMENT}

I express my deep sense of gratitude to my department staff and SHIATS for providing all facilities for my work. I am thankful to my friend Abdul Suhel, student M.Tech Agricultural Engineering, SHIATS for helping me throughout this work.

\section{REFERENCES}

[1] Tong, C.H., Lund, D.B., 1990. Effective moisture diffusivity in porous materials as a function of temperature and moisture content. Biotechnology Progress 6, 67-75.

[2] Ozilgen, M., Heil, J.R., 1994. Mathematical modelling of transient heat and mass transport in a baking process. Journal of Food Processing and Preservation 18, 133-148.

[3] Carvalho, M. and Martins, N., 1993. Mathematical modelling of heat and mass transfer in a forced convection baking oven. AICHE Symposium Series - Heat Transfer 88 (288), 205-211.

[4] Fellows, P.J., (2000). Food Processing Technology-Principles and Practice. Wood head Publishing Limited, Cambridge.

[5] Therdthai Nantawan, Zhou Weibiao and Thomas Adamczak, 2003. Three-dimensional CFD modelling and simulation of the temperature profiles and airflow patterns during a continuous industrial baking process. Journal of Food Engineering 65, 599-608. 